\title{
FAMILIAL SPONDYLOLISTHESIS OF THE AXIS VERTEBRA
}

\author{
R. E. A. NORDSTRÖM. T. V. LAHDENRANTA. I. I. KAITILA. E. M. I. LAASONEN
}

\author{
From Helsinki University Central Hospital
}

\begin{abstract}
This report describes a nine-year-old girl with a spondylolisthesis of the $\mathrm{C} 2$ vertebra allowing $14 \mathrm{~mm}$ of slip. Her father had very similar vertebral anomalies.
\end{abstract}

In contrast to the lumbar spine, spondylolysis and spondylolisthesis involving the cervical spine is very uncommon, only 27 cases of spondylolysis and 22 of spondylolisthesis having been reported (Dawley 1971; Fardon and Fielding 1981). Only three cases involving the axis vertebra have been described and only one of these had spondylolisthesis of the second on the third vertebra. We report a girl with spondylolisthesis of the axis and other vertebral and minor skeletal anomalies. The family history suggests an autosomal dominant inheritance of this condition.

\section{CASE REPORT}

A nine-year-old girl, the only child of the family, was referred after she had fallen on her back. She complained of mild local neck pain with no radiation and no neurological abnormality and had no previous history of spinal injury. She was slender with disproportionately long extremities and a slightly elongated neck. Her height was $140 \mathrm{~cm}$ and her span $152 \mathrm{~cm}$, suggesting some marfanoid disproportion. Her fingers were long and narrow with broader distal segments and nails. Her neck movements were normal as were her cardiovascular and respiratory systems. She had slight hypertelorism but no visual impairment or lens dislocation.

Radiographs showed each pars interarticularis of the axis to be about twice the normal length with elongated inferior articular surfaces, and bilateral anteriorly placed spondylolysis (Figs I. 2 and 3). In full extension the posterior surfaces of $\mathrm{C} 2$ and $\mathrm{C} 3$ were in line with the other vertebrae but in full flexion C2 slipped $14 \mathrm{~mm}$ anteriorly on $\mathrm{C} 3$, with tilting at this level from -12 to +13 . Tilt also occurred at the spondylolytic defect,

R. F. A. Nordström. MI)

Annankittu II B II, (0)120) Helsinki 12. Finland.

T. V. Lahdenranta, MD

E. M. I. Laasonen. MD

Department of Orthopaedics and Traumatology. Helsinki University Central Hospital, Helsinki, Finland.

I. I. Kaitila, MD

Department of Medical Genetics. University of Helsinki, Finland.

Requests for reprints should be sent to Dr R. E. A. Nordström

(. 1986 British Editorial Society of Bone and Joint Surgery $0301620 \times 865163 \$ 2.00$ changing the angle between the spinous process and the inferior surface of the body from 29 to 56 . The body of C6 was dysplastic and showed bilateral spondylolysis with minimal slip. Radiographs showed spina bifida of C2, C6, T12, L1, L5, S1 and S2 vertebrae. The metacarpal index of her hand was 10.2 , clearly exceeding the normal value of 7.9 at this age (Eldridge 1964; Rand et al. 1980). The second and the third metacarpals were elongated (Fig. 4) as were the second and the third metatarsal bones. Radiographs of the skull and the chest showed no abnormalities.

In view of the unusual nature of the case, the patient was treated with skull traction for six days and then wore a neck support for six weeks. At no time did she show any abnormal neurological signs, despite the $14 \mathrm{~mm}$ amplitude of instability. No operative treatment was offered and she was allowed to mobilise her neck freely.

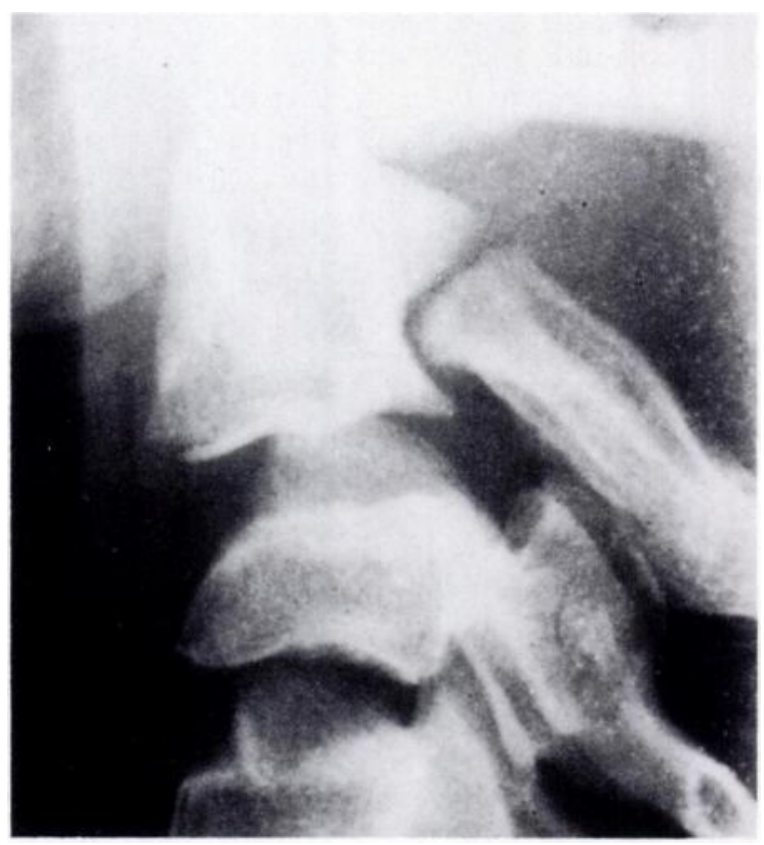

Fig. 1

Lateral radiograph of the upper cervical spine taken soon after the episode of minor trauma to show the chronic defect and long pars interarticularis of the axis vertebra. 


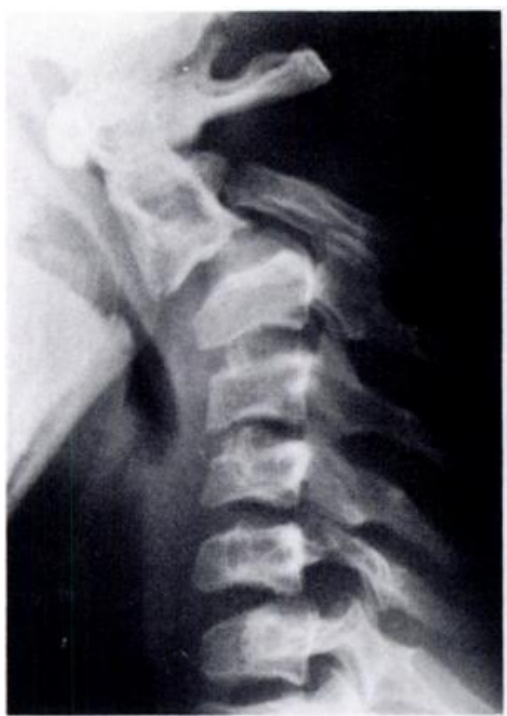

Fig. 2

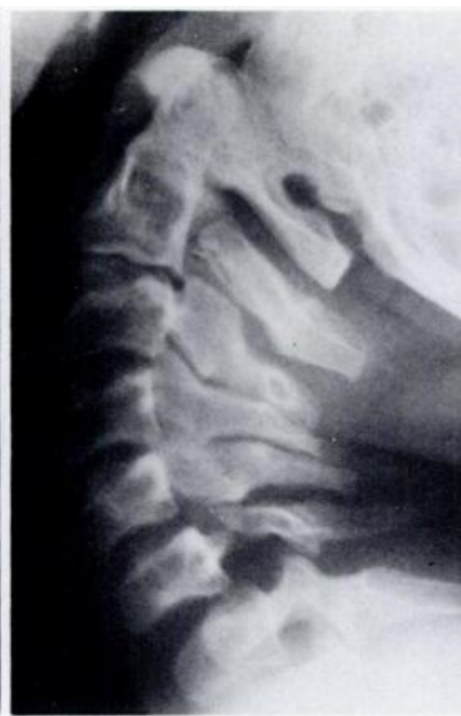

Fig. 3

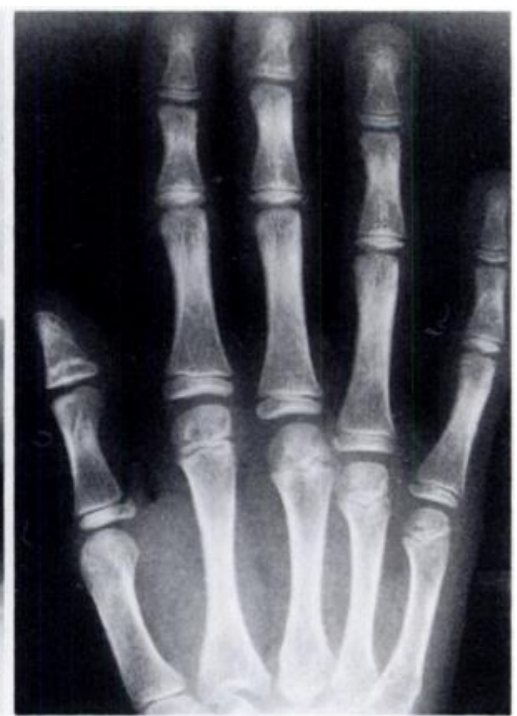

Fig. 4

Figures 2 and 3-Flexion and extension radiographs of the eervical spine taken 19 months later. In flexion the superior articular surfaces of $\mathrm{C} 3$ lie against the posterior parts of the elongated inferior articular surfaces of $\mathrm{C}_{2}$. In extension they articulate with the anterior part of the articular surfaces. Note the angular movement of the lamina of $C 2$ in flexion and extension. and the spondylolysis of C 6 vertebra. Figure 4--Radiograph of the right hand to show the long second and third metacarpals with slightly short phalanges in these fingers.

At review one year and seven months after the minor injury she had no symptoms that could be referred to the spondylolisthesis and had led a normal life, taking part in sport activities at school.

Family history. The patients'37-year-old father mentioned that he had suffered mild transient low back pain 10 years previously. On examination he also showed disproportionately long extremities, but had a short neck and a slight thoracocervical kyphosis. His fingers were long and slightly hyperextensible with short and broad distal phalanges and flattened nails like those of his daughter. He also had elongated second and third metacarpals and metatarsals, with a metacarpal index of 8.2. His height was $183 \mathrm{~cm}$ and his span $202 \mathrm{~cm}$. He had normal cardiovascular and respiratory systems and normal vision.

Radiographs of his cervical spine (Fig. 5) showed a bilateral corticated spondylolysis of $\mathrm{C} 2$ with a $2 \mathrm{~mm}$ forward slip of $\mathrm{C} 2$ on $\mathrm{C} 3$ in full flexion which was fully corrected in extension. His C6 vertebra showed dysplasia and spondylolysis. This was remarkably similar to the situation in his daughter except that he had only slight elongation of the pars interarticularis of the axis. The girl's father has one sister and six brothers, but neither his parents nor any of his siblings had a history of spinal problems.

\section{DISCUSSION}

A number of studies have shown that the dysplastic type of lumbosacral spondylolysis and spondylolisthesis has a monogenic aetiology, and that the mode of inheritance of the condition is autosomal dominant with reduced penetrance (Amuso and Mankin 1967; Taillard 1976;
Wiltse. Newman and Macnab 1976: Haukipuro et al. 1978; Albanese and Pizzutillo 1982). Associated anomalies of the lumbar vertebrae, such as spina bifida, have been frequently reported, but other regions of the spine had not been examined in these cases.

Our case suggests the need for careful clinical and possibly radiographic evaluation of patients with cervical spondylolisthesis or spondylolysis for other vertebral or skeletal anomalies. Furthermore, in view of the autosomal dominant mode of inheritance other members of

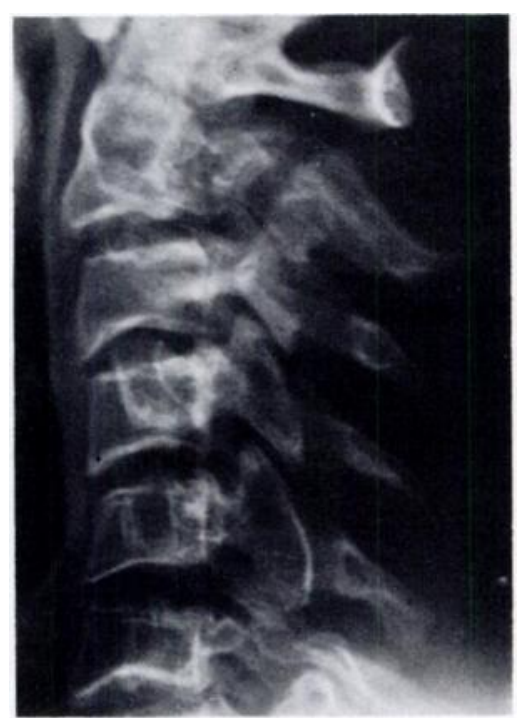

Fig. 5

Lateral radiograph of the cervical spine of the patient $s$ father to show spondylolysis of $C^{2}$ with a forward slipping of $2 \mathrm{~mm}$ on $\mathrm{C} 3$ and dysplasia of $\mathrm{C}^{\prime} \mathrm{C}$ with spondylolysis. 
the family should also be examined. It would appear that the clinical expression of the condition may be variable, and even non-penetrance may be encountered.

\section{REFERENCES}

Albanese M, Pizzutillo PD. Family study of spondylolysis and spondylolisthesis. J Pediatr Orthop 1982:2:496-99.

Amuso SJ, Mankin HJ. Hereditary spondylolisthesis and spina bifida: report of a family in which the lesion is transmitted as an autosomal dominant through three generations. J Bone Joint Surg [Am] 1967:49-A:507-13.

Dawley JA. Spondylolisthesis of the cervical spine: case report. $J$ Neurosurg 1971:34:99 101.
Eldridge R. The metacarpal index: a useful aid in the diagnosis of the Marfan syndrome. Arch Intern Med 1964:113:248-54.

Fardon DF, Fielding JW. Defects of the pedicle and spondylolisthesis of the second cervical vertebra. J Bone Joint Surg [Br] 1981;63-B: $526-8$.

Haukipuro K, Keränen N, Koivisto E, Lindholm R, Norio R, Punto L. Familial occurrence of lumbar spondylolysis and spondylolisthesis. Clin Genet 1978;13:471-6.

Rand TC, Edwards DK, Bay CA, Jones KL. The metacarpal index in normal children. Pediatr Radiol 1980:9:31 2.

Taillard WF. Etiology of spondylolisthesis. Clin Orthop 1976;117: 309.

Wiltse LL, Newman PH, Macnab I. Classification of spondylolisis and spondylolisthesis. Clin Orthop 1976;117:23-9.

BRIEF REPORT

\section{SCIATICA CAUSED BY PERIFIBROSIS OF THE SCIATIC NERVE}

\section{ULRIK MERRILD, IB SØGAARD}

Case report. A 39-year-old man was admitted with a history of right sciatica without pain in his back. He had never had symptoms from his back or legs until six months earlier when he fell two metres into a pit, landing on his right buttock. Since then he had had right sciatica extending down to the outer aspect of the ankle after sitting for more than 10 minutes. Conservative treatment had no effect. On admission he had reduced sensation to touch and to pain on the lateral aspect of his right calf and in the first dorsal web space of his foot, slight weakness of dorsiflexion of his ankle and hallux, a positive Lasègue's sign at 60 , and a positive Tinel sign over the sciatic nerve in the mid-thigh. The tendon reflexes were normal. Radiographs of his lumbosacral spine showed spondylolisthesis at $\mathrm{L} 4 / 5$, with only slight forward slip. Myelography demonstrated slight shortening of the right fifth lumbar nerve root.

At exploration through a right partial hemilaminectomy no intervertebral laxity was demonstrated and there was no disc herniation. Three weeks after this operation his symptoms recurred and once again conservative treatment had no effect. When he was readmit-

U. Merrild, MD, Surgeon

1. Søgaard. MD. Chief Surgeon

Department of Neurosurgery. The University Hospital of Odense, DK-5000, Odense C. Denmark.

Correspondence to Dr Merrild.

- 1986 British Editorial Society of Bone and Joint Surgery $0301620 \mathrm{X} / 86 / 5 \mathrm{RO} 2 \$ 2.00$ ted three months later, his signs, including the positive Tinel sign, were unchanged. A CT scan of the lumbar spine showed no disc herniation. Electromyography supported the clinical suspicion of damage to the sciatic nerve itself, with a partial block to conduction. At operation the nerve was found to be surrounded by tight fibrosis in the gluteal region and was decompressed.

Six months later the patient had resumed his job as a policeman. His signs and symptoms had subsided, leaving only slight wasting of the thigh; the Tinel sign and the Lasègue sign were both negative.

Discussion. Sciatic nerve damage causing pain radiating distally is unusual (see references). The following characteristics should arouse suspicion: a history of direct trauma to the nerve; aggravation of symptoms when pressure is applied, for example, by sitting; a positive Tinel sign; exclusion of a herniated disc by myelography or CT scan; and an electromyogram compatible with a sciatic nerve block. None of these findings is specific and a definitive diagnosis can only be achieved if, at operation, the nerve is found to be compressed and if signs and symptoms subside after decompression. Electromyography is probably the most useful diagnostic aid.

\section{REFERENCES}

Banerjee T, Hall CD. Sciatic entrapment neuropathy: case report. $J$ Neurosurg 1976;45:216-7.

Richardson RR, Hahn YS, Siqueira EB. Intraneural hematoma of the sciatic nerve: case report. J Neurosurg 1978:49:298-300.

Segaard I. Sciatic nerve entrapment: case report. J Neurosurg 1983:58: 2756. 